\title{
Teaching NeuroImages: Neuroimaging in Adult-Onset Alexander Disease
}

Neethu Gopal, MBBS, Vivek Gupta, MD, Lindsy N. Williams, MD, and Sukhwinder J.S. Sandhu, MD

Neurolog $y^{\circledR}$ 2021;96:e814-e815. doi:10.1212/WNL.0000000000010803

Figure MRI of the Cervical Spine and Brain
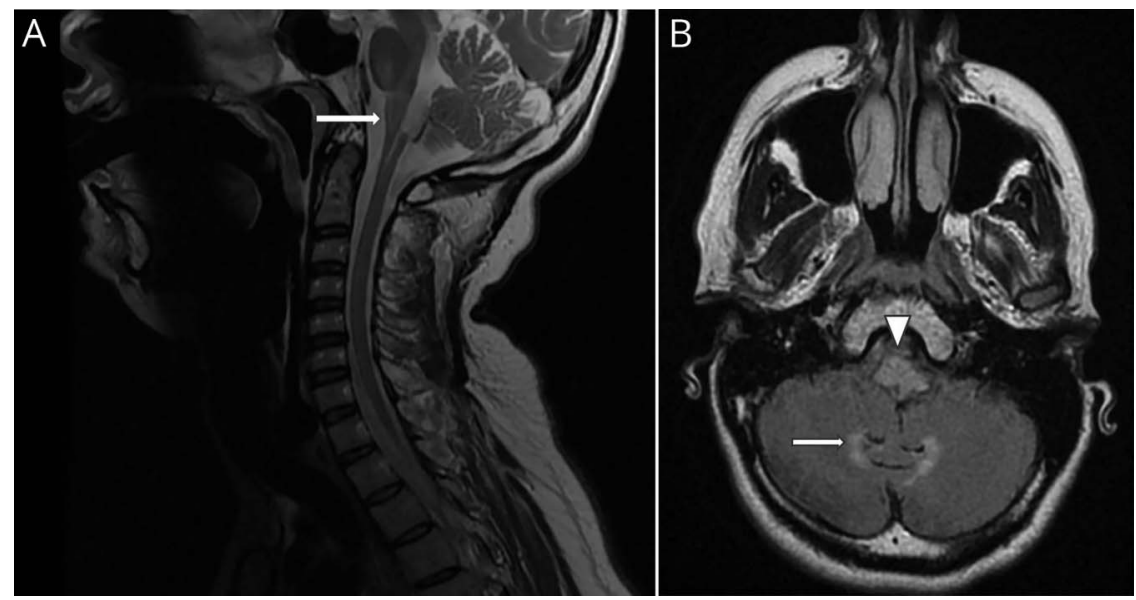

(A) Sagittal T2-weighted imaging along the midline demonstrates atrophy of the cervical medullary junction (arrow). (B) Axial T2 FLAIR image reveals hyperintense T2 FLAIR signal in the bilateral dentate nuclei (arrow). Medullary atrophy also noted with abnormal signal (arrowhead).

A 35-year-old woman presented with gait disturbance, generalized stiffness, difficulty swallowing, and bladder incontinence for the past 3 years. Neurologic evaluation revealed brisk deep tendon reflexes in all 4 limbs and bilateral Hoffman signs. Her family history was significant for a brother diagnosed through genetic testing with Adult-onset Alexander disease (AOAD) at age 28. MRI head and cervical spine (figure A and B) showed classic signs of AOAD. Genetic testing confirmed glial fibrillary acidic protein gene mutation R239G consistent with AOAD. Although infantile Alexander Disease is more common, these unique MRI findings should raise suspicion of AOAD and prompt consideration for genetic testing. ${ }^{1,2}$

\section{Study Funding}

No targeted funding reported.

\section{Disclosure}

The authors report no dislcosures relevant to the manuscript. Go to Neurology.org/N for full disclosures.

\section{Correspondence}

Dr. Sandhu

Sandhu.Johnny@mayo.edu

\section{MORE ONLINE}

$\rightarrow$ Teaching slides

links.lww.com/WNL/

B210 


\begin{tabular}{lll}
\hline \multicolumn{2}{l}{ Appendix Authors } & \\
\hline Name & Location & Contribution \\
\hline $\begin{array}{l}\text { Neethu Gopal, } \\
\text { MBBS }\end{array}$ & $\begin{array}{l}\text { Department of } \\
\text { Neurology, Mayo Clinic, } \\
\text { Florida }\end{array}$ & $\begin{array}{l}\text { Execution, writing of the } \\
\text { first draft, and review }\end{array}$ \\
\hline $\begin{array}{l}\text { Vivek Gupta, } \\
\text { MD }\end{array}$ & $\begin{array}{l}\text { Department of } \\
\text { Radiology, Mayo Clinic, } \\
\text { Florida }\end{array}$ & $\begin{array}{l}\text { Execution, review, and } \\
\text { critique }\end{array}$ \\
\hline $\begin{array}{l}\text { Lindsy N. } \\
\text { Williams, MD }\end{array}$ & $\begin{array}{l}\text { Department of } \\
\text { Neurology, Mayo Clinic, } \\
\text { Florida }\end{array}$ & $\begin{array}{l}\text { Execution, review, and } \\
\text { critique }\end{array}$ \\
\hline $\begin{array}{l}\text { Sukhwinder } \\
\text { J.S. Sandhu, MD }\end{array}$ & $\begin{array}{l}\text { Department of } \\
\text { Radiology, Mayo Clinic, } \\
\text { Florida }\end{array}$ & $\begin{array}{l}\text { MRI description, } \\
\text { execution, review, and } \\
\text { critique }\end{array}$ \\
\hline
\end{tabular}

\section{References}

1. van der Knaap MS, Salomons GS, Li R, et al. Unusual variants of Alexander's disease. Ann Neurol 2005;57:327-338.

2. Farina L, Pareyson D, Minati L, et al. Can MR imaging diagnose adult-onset Alexander disease? AJNR Am J Neuroradiol 2008;29:1190-1196. 


\section{Neurology}

\section{Teaching NeuroImages: Neuroimaging in Adult-Onset Alexander Disease \\ Neethu Gopal, Vivek Gupta, Lindsy N. Williams, et al.}

Neurology 2021;96;e814-e815 Published Online before print September 11, 2020

DOI 10.1212/WNL.0000000000010803

This information is current as of September 11, 2020

Updated Information \&

Services

References

Subspecialty Collections

Permissions \& Licensing

Reprints including high resolution figures, can be found at: http://n.neurology.org/content/96/5/e814.full

This article cites 2 articles, 1 of which you can access for free at: http://n.neurology.org/content/96/5/e814.full\#ref-list-1

This article, along with others on similar topics, appears in the following collection(s):

\section{All Genetics}

http://n.neurology.org/cgi/collection/all_genetics

Leukodystrophies

http://n.neurology.org/cgi/collection/leukodystrophies

Information about reproducing this article in parts (figures,tables) or in its entirety can be found online at:

http://www.neurology.org/about/about_the_journal\#permissions

Information about ordering reprints can be found online:

http://n.neurology.org/subscribers/advertise

Neurology ${ }^{\circledR}$ is the official journal of the American Academy of Neurology. Published continuously since 1951, it is now a weekly with 48 issues per year. Copyright @ 2020 American Academy of Neurology. All rights reserved. Print ISSN: 0028-3878. Online ISSN: 1526-632X.

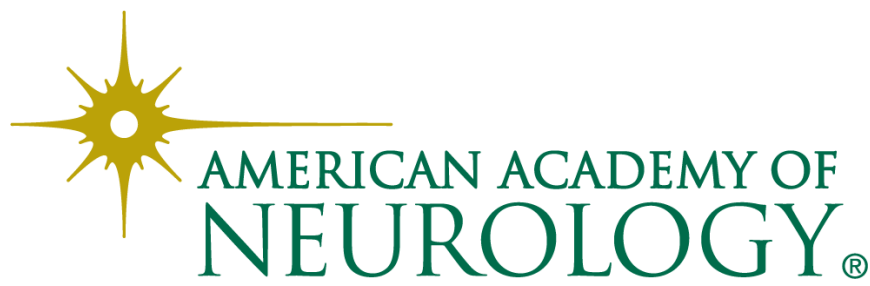

